\title{
The Analysis on the Value of Yongsan National Park and its Economic Effect
}

\author{
In-Seok Chang ${ }^{1}$, Young-Tae $\mathrm{Cho}^{2}$, Mi-Hong $\mathrm{Lee}^{3}$ and Shin-Won Park ${ }^{4}$ \\ (Received September 6, 2011 / Revised September 30, 2011 / Accepted October 19, 2011)
}

\begin{abstract}
This study estimated economic value and benefits of Yongsan National Park, which will be constructed by financial investment of the government and objectively estimated the real value of it by understanding the value of the park from a user's view of the park. For this, the value of Yongsan National Park is divided into using value such as carbon reduction and the function of relieving urban heat island as an environmental material and non-using value based on willingness to pay of the public according to the construction of the park. As a result of the analysis, it was found out that the using value of Yongsan National Park would reach 130 million won up to maximum level of 450 million won per year, and the non-using value was analyzed to be worthy of 2,344 won per capita every month. Besides, economic ripple effect that can be expected in the process of the park construction project was analyzed to be a national policy that creates effect on production inducement of 2.6 trillion won and value added of 809.6 billion won and new jobs for 25,620 persons.

Considering the value of Yongsan National Park and the effect of the project based on the result of this study, it was found that it could sufficiently secure the validity of implementing the project compared to the financial investment by the government. Therefore, it must be emphasized that diffusion strategy is necessary for national understanding and for a nation to make it understood its appropriateness widely in respect to the construction of Yongsan National Park for the successful construction of Yongsan National Park and to raise its using value in the future.
\end{abstract}

Keywords: Yongsan National Park, Using Value, Non-Using Value, Conjoint Analysis, Economic Spill Over

\section{Introduction}

\subsection{Background and Objectives}

Yongsan National Park area was a foreign army post for a long time since Koryo Dynasty, and the park is constructed taking an opportunity of restitution of U.S. Army base so far.

But it will be a national policy project for the construction of a national park progressed by the financial investment by the government at 2015 .

As such, national financial commitment by the composition of the Yongsan Park, a national awareness to increase the full-scale business promotion previously, which thecomposition of public goods supply in terms of access and people to recognize the park's value and effectiveness of academic measures the need to look at have them.

Estimating the value of the park to be Yongsan justification, despite the meantime, Yongsan park composition with a focus on political and social issues much empirical research is lacking.

Especially political and social controversy in terms of pure public goods supply will of the people reported estimate reflects the value of the park, its meaning and to increase the value of the future will require a renewed commitment to do.

This study intends to take view of the value of Yongsan National Park and the effect of the project in the aspect that since Yongsan park is a national park, the main agent of its benefits and costs must be the whole nation and the ultimate enforcement cost of the policy is from the taxes of the people.

Therefore, this research is intended to draw political implications that could increase using value of the park through the estimation of value evaluation on intrinsic function that Yongsan park and a ripple effect derived from the process of the project based on the direction of construction of Yongsan park that has been discussed in the meantime.

This paper studies that the authors participated in The Study on the Value of Yongsan Park and its Construction Effect (2010) by Ministry of Land, Transport and Maritime Affairs, which analyzed the restructuring and depth.

1) Research Fellow, Land \& Housing Institute (Main author: changis@lh.or.kr)

2) Research Fellow, Land \& Housing Institute (Corresponding author: ump2000@empal.com)

3) Research Fellow, Land \& Housing Institute

4) Researcher, Land \& Housing Institute 


\subsection{Research Method}

This study consists of three phases. First, there is a part that introduces the background of the construction of Yongsan park and urban spatial features through policy data, literature investigation etc. Second, national expectation and social evaluation on the construction of Yongsan park are investigated and the value of Yongsan park on which willingness to pay is reflected is analyzed through the survey on a people in the value analysis of a people's evaluation on Yongsan park. Lastly, it is intended to estimate economic, sociocultural, and environmental ripple effect of the construction project on the basis of the project cost that is invested into Yongsan park.

Yongsan park, which is the subject of this study, is assumed that the project will be started in 2015 , and will have preliminary opening in 2017, secondary opening in 2019 and then will be completed in 2040 based on ${ }^{『}$ The Special Law on Constructing Yongsan Park』that was enforced in January, 2008.

Besides, the spatial scope of the analysis is the main site, which

\begin{tabular}{c|c}
\hline 1st Step & $\begin{array}{c}\text { Background of Construction of Yongsan Park and } \\
\text { Understanding Urban Spatial Features }\end{array}$ \\
\hline
\end{tabular}

Understanding background of the park construction project according to the return of military bases and understanding structural specialty of the urban park construction project by the national finance project

$\Rightarrow$ Literature investigation, collection and arrangement of basic data

\begin{tabular}{|c|c|}
\hline \multicolumn{2}{|r|}{$\boldsymbol{\nabla}$} \\
\hline & \\
\hline \multicolumn{2}{|c|}{$\begin{array}{l}\text { - National expectation and social evaluation on the construction of } \\
\text { Yongsan park } \\
\text { - Quantification of national cognition on functions and values of } \\
\text { Yongsan park } \\
\Rightarrow \text { Literature investigation (Replacement Cost Method), survey (conjoint } \\
\text { analysis) }\end{array}$} \\
\hline \multicolumn{2}{|r|}{$\nabla$} \\
\hline 3rd Step & 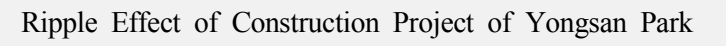 \\
\hline \multicolumn{2}{|c|}{$\begin{array}{l}\text { - Estimation of economic ripple effect of the park construction project } \\
\text { - Price increase of real estate and increase effect of local tax revenue } \\
\text { according to the construction of the park } \\
\text { - Analysis of tourists' flow on introduction of tourism } \\
\Rightarrow \text { Input-output model, literature search (Replacement Cost Method) }\end{array}$} \\
\hline
\end{tabular}

Fig. 1. Process \& Contents is the construction site for Yongsan park, 2,677 thousand $\mathrm{m}^{2}$ that is supposed to be returned by U.S. Army and surrounding mountainous land and surrounding regions.

Yongsan park claims to advocate a park without completion to develop endlessly and expand the purpose of utilization, but this study was based on the year of 2017 as the preliminary opening point of Yongsan park since the setup of a time importantly acts for the effectiveness analysis of the construction project of the park.

\subsection{Review of Previous Studies}

Related to the topic of this study estimated the value of the park as public goods are extremely limited research has been made up, and analysis capabilities of the park as a public good did not fully reflect the property there are limitations.

First, estimated the value of the park are all related to representative studies are six. Among them, the citizens of Seoul which include the most recent study conducted at the target in the woods by applying a conditional value estimation estimates the results of the economic value of the park, the park has an area of $1,156,498$ economic value was calculated as $16.8-19.2$ billion won.

On the other hand, Yongsan park to target the estimated value of the park is extremely limited in the range of research until now is all there is two side, analyzing the target area in the Seoul area is limited enough to measure the value of the park. Joe hyeong gyu (2001) TCM (Travel Cost Method) results in the estimated value by the Yongsan park, Yongsan park is about the economic value estimated at 66.7 to 71.1 billion won was level. On nu ri (2008) with estimation of the conditional value to the citizens of Seoul estimated 202 patients results, Yongsan, the value of the park's environmental benefits were estimated to be approximately 157.7 billion won.

\subsection{Differences with Previous Studies}

However, ensuring the objectivity of the study results are derived is a difficult situation, Travel cost approach by applying the full value of the park that does not reflect the unused limit exists. As seen earlier, the value estimated for the Yongsan park was made objectively.

Table 1. Previous Studies for the Value of Park

\begin{tabular}{|c|c|c|c|c|c|}
\hline & Park & Method & Area $\left(\mathrm{m}^{2}\right)$ & Economic Value (billion) & Year \\
\hline \multirow[b]{2}{*}{ Urban Park } & Youido Park & CVM & 229,539 & $36.1 \sim 38.3$ & 1998 \\
\hline & Citizen Forest & CVM & 258,991 & $40.4 \sim 43.8$ & 1994 \\
\hline \multirow[b]{2}{*}{ Non Urban Park } & Everland & TCM & 991,740 & 8.88 & 1998 \\
\hline & Chungju Lake & Expenditure Approach & - & 5.4 & 1990 \\
\hline
\end{tabular}

source: Joe Hyeong Gyu (2001), "A Study of Economic Value of Urban Park After Changes of Environments" 
Table 2. Domestic Large-Scaled Urban Parks

\begin{tabular}{c|c|c|c|c}
\hline Name & Constructed Year & Scale $\left(1,000 \mathrm{~m}^{2}\right)$ & Main Agent of Construction & Main Function \\
\hline Ulsan Grand Park & 2006 & 3,663 & Ulsan City, SK & Spare Time, Leisure \\
\hline Independence Park & 1992 & 109 & Seoul City & History, Culture \\
\hline Olympic Park & 1986 & 1,512 & GovernmentSeoul City & Spare Time, Leisure, History \\
\hline Seoul Forest & 2005 & 1,556 & Seoul City & Ecology, Green Land \\
\hline Sun Yu Island Park & 2002 & 110 & Seoul City & Culture, Leisure \\
\hline Yongsan Family Park & 1992 & 89 & Government Seoul City & Culture, Leisure \\
\hline
\end{tabular}

In addition, the park is classified as public goods value estimate for this estimation also introduce the conditional value dimension that is determined from the somewhat passive done.

In particular, applying the CVM (Contingent Valuation Method), Yongsan, in previous studies when applied to the park, the park's difficult to set various preference schemes for the intrinsic value of the property difficult to estimate, in fact, has limitations.

In contrast with this study on the conjoint analysis of Yongsan Park on the properties and features a wide selection of alternatives was presented, based on the results of that analysis is in progress, national business policy implications for the direction of the composition park derivation is possible there is a distinction

\section{Background of the Construction of Yongsan Park and Diagrammatic Understanding}

\subsection{Background of Construction and Overview}

The ${ }^{\circledR}$ Special law on the construction of Yongsan park $\_$was established in 2007 taking an opportunity of the agreement on moving Yongsan base between Korea and U.S. summit in 2003. According to the special law on the construction of Yongsan park, the basic ideology of Yongsan park has the aim that people enjoy various benefits widely by constructing it into recreational space and natural ecological space etc. by a people possessing ethnicity, historicity, and culture. The basic philosophy of Yongsan park means that a park aiming at the future, an open-type park along with the people, a continuously growing park, and 4) a national park opened towards the world.

The area of the land that is scheduled for Yongsan park is $2,458,000 \mathrm{~m}^{2}$ except for the remaining land in accordance with the agreement between Korea and U.S. among around 2,678,000 $\mathrm{m}^{2}$ of the main land. In the case of including adjacent War Memorial, Yongsan Family Park and National Museum of Korea in the park, the total area of Yongsan park is approximately $2,935,000 \mathrm{~m}^{2}$. On the western side of Yongsan site, the district for the usage of commerce and offices centering around Han River road and Yongsan Electronics Shopping Mall is located, and the other districts are mostly residential area, which is a region that residence and commerce are superior.

\subsection{History and Futurity of Yongsan Park}

The Yongsan area was used for logistics base of Mongol army at late Koryo, and for a supply base of Japanese army at Japanese Invasion of Korea in 1592, and since the Sino-Japanese War of 1894, army from Qing dynasty and Japanese army were stationed. In the process of requisition of Japanese bases by U.S. army along with liberation on Aug. 15th in 1945, they naturally became U.S. army posts. Since then, despite the development of Gangnam and the construction of Dongjak bridge etc. in 1970s, Yongsan area is military facility, which becomes an obstacle against urban planning.

However, on the premise of relocation of U.S. army bases, Yongsan area is planned to be a subcenter of a metropolis on the center axis to connect downtown with Youngdeongpo and Youngdong in Seoul City Basic Plan for the year of 2020. For more details, Yongsan area is planned to be induced to combined development of conference, hotels, commerce, culture and residential function with the main usage of international affairs function and to be promoted as a center possible for 24-hour activities. Besides, Yongsan park is being planned to be the park green land of downtown considering connection with ecological green land axis and Han river green land axis that are linked with Mt. Bukhan- Namsan-Yongsan-Han river-Mt.Gwanak.

\subsection{Domestic Urban Park}

Urban parks are not only places for recreational activities, refinement of emotions, culture and leisure activities, but also have an important role and function to make the urban landscape be beautiful by making the artificial environment harmonized with natural environment (Park, Ji Ho et al, 2004). The biggest one of domestic urban parks is Ulsan Grand Park which reaches 3,683thousand $\mathrm{m}^{2}$, and it was constructed through donation of a private company (SK). On the other hand, in the process of urban park construction, there is none for the cases by the central government except for Olympic Park and Yongsan Family Park. For the Olympic Park, the central government established a plan for the park construction to celebrate Seoul Olympic in 1988 but Seoul City was in charge of progressing the project 1 ).

1) At that time, since it was the time before the local autonomous entity is inaugurated, even though Seoul City fully covered the project cost, it's difficult to conclude that there is no role of the central government. 
Table 3. Oversea Urban Parks

\begin{tabular}{c|c|c|c|c}
\hline City & Area $\left(\mathrm{km}^{2}\right)$ & Population $(10,000)$ & Representative Park $\left(1000 \mathrm{~m}^{2}\right)$ \\
\hline London & 1,578 & 751 & Hyde Park & 1,420 \\
\hline New York & 1,214 & 821 & Central Park & 3,394 \\
\hline Paris & 2,723 & 993 & Bois de Boulogne & 8,450 \\
\hline Toronto & 630 & 250 & Downsview Park & 2,315 \\
\hline Tokyo & 2,187 & 1,287 & Ueno Park & 620 \\
\hline Seoul & 605 & 1,046 & Yongsan Park & 2,677 \\
\hline
\end{tabular}

Table 4. Classification of Types of Value Estimation Methods

\begin{tabular}{|c|c|c|}
\hline Functions of Yongsan Park & Using Value & Non-Using Value \\
\hline Symbolism $\cdot$ Historicity & \multirow{4}{*}{ (Not Analyzed) } & \multirow{4}{*}{ - Conjoint Analysis } \\
\hline Health $\cdot$ Aesthetic Stability & & \\
\hline Relaxation $\cdot$ Amusement & & \\
\hline Culture Arts Experience & & \\
\hline $\begin{array}{c}\text { Environment } \\
\text { Ecology }\end{array}$ & $\begin{array}{l}\text { - Carbon Reduction (CER: Certified Emission Reduction) } \\
\text { - Purification of Air Pollution (Replacement Cost Method) } \\
\text { - Improvement of Air Pollution (Replacement Cost Method) } \\
\text { - Urban Heat Island Mitigation (Replacement Cost Method) }\end{array}$ & - \\
\hline
\end{tabular}

\subsection{Oversea Case of Urban Parks}

Yongsan park can be compared with foreign large-scaled urban parks such as Hyde Park (London), Central Park (New York), Bois de Boulogne (Paris), Ueno Park (Tokyo). Most foreign large-scaled urban parks perform the general cultural function by locating large facilities, and actively utilize waterfronts space such as boating, and outdoor swimming pools, etc (Ministry of Land, Transport, and Maritime Affairs, The Study on Each Field of Yongsan Park for the Construction of Brand- Name Park, 2009). The cases that a nation constructs the urban park includes Downsview Park in Canada, Presidio Park in the States, Showa Park in Japan etc. In the case that a nation constructs the urban park, memorial facilities are partially installed to represent national historicity, symbolism and facilities related with folklore or tradition are actively installed and operated.

\section{Value Estimation of Yongsan Park}

\subsection{Research Design}

Valuation of goods means the size of subjective utility that a user feels by using those goods for the function and attributes that goods themselves intrinsically possess. Therefore, estimating valuation of goods can be considered not to presume ideal level or justifiable remuneration that a supplier of goods wishes but to be a process to estimate the level of attributes of goods into monetary value with a user's perspective.

Unlike market commodities, since public goods like Yongsan park which is the subject of this study don't have market price or it's actually impossible to earmark the market price, various value estimation methods must be applied depending on how functions and attributes of the corresponding goods are specified.

The value of public goods are classified into using value and non-using value depending on the level of utility that users expect. It is necessary to estimate the total value including using value and non-using value to estimate the value of Yongsan park which is public goods as well as non-market goods.

There are various discussions about the typology for the functions of urban parks but it can be generally classified into relaxation·amusement, historicity $\cdot$ symbolism, health $\cdot$ aesthetic stability, culture - arts experience, environment - ecology, etc (Son, Sang Rak, Kwon, Sang Jun, 2001). This study is intended to understand using value of Yongsan park through the effect of carbon reduction according to environmental preservation and ecological function and reduction effect of air pollution, effect of urban heat island relief by translating the value into the effect that appears since Yongsan park is constructed. Other than that, the functions of Yongsan park such as historicity •symbolism would be understood with non-using value.

As for the estimation method of non-using value, Conjoint Analysis ${ }^{2}$ ) among stated preference techniques ${ }^{3}$ ) that after respondents understand various optional alternatives with attributes and functions of Yongsan park, they choose willingness to pay was applied.

2) Travel Cost Method (TCM), Contingent Valuation Method (CVM), Conjoint Analysis

3) Unlike the existing cost using valuation estimation method, Conjoint Analysis has an advantage that it's possible to estimate valuation for the true nature of the goods that doesn't exist or for the goods that are scheduled to be supplied in the future, and especially it can suggest the basis and direction of various policy making on the supply of the public goods. Like recent Yongsan park, Conjoint Analysis is mostly being used for the valuation estimation method of the public goods with indefinite true nature. (Gwak, Seung Jun et al, valuation estimation for pubic interests of museum facilities, 2007, valuation estimation of the mouth of Geum River 2006, Estimation of environmental cost by the effect of air pollution in Seoul City 2005.) 


\subsection{Estimation of Using Value}

In this study, using value of environmental $\cdot$ ecological functions were estimated on the basis of $41 \%$ of the green land ratio of Yongsan park.

It is judged that the using value according to the construction of Yongsan park could largely have carbon reduction function, purification function of air pollution according to the purification of $\mathrm{NO}_{2}, \mathrm{SO}_{2}$ and cost-reducing effect in accordance with health improvement and is able to decline air temperature so that the effect of urban heat island mitigation was estimated for the construction park.

\subsubsection{Carbon Reduction}

The carbon reduction function according to the construction of Yongsan park is possible to be calculated by dividing it into the amount of absorption and the amount of stock. If the result of the preceding related with absorption and storage of $\mathrm{CO}_{2}$ by domestic green land, the scope of average amount of absorption is 1.54 ton/ha/yr (Hanbat arboretum) 24.6ton/ha/yr (Namsan Park), and the scope of storage amount is 36.3ton/ha (Hyowon Park) 293.8ton/ha (Namsan Park). In this study, the trading price of carbon emission was as of Aug. 2010 of European Climate Exchange. If the market value of carbon reduction according to the construction of Yongsan park in accordance with the $\mathrm{CO}_{2}$ absorption amount of trees and the scenario by each area of green land, the amount of absorption is 3,128 thousand won to 111,143 thousand won, and the amount of stock is 73,736 thousand won to $1,327,388$ thousand won. The stock amount of $\mathrm{CO}_{2}$ is the stock that trees or forest itself possesses, and the absorption amount of $\mathrm{CO}_{2}$ means the amount $\mathrm{CO}_{2}$ that trees absorb every year. Therefore, the unit of stock amount of $\mathrm{CO}_{2}$ is the stock amount of carbon dioxide per the unit area, and the unit of absorption amount is the annual absorption amount per the unit area. Hence, for using value according to the carbon reduction function, both units must not be simply added, but it is reasonable to include only the amount of absorption in the ripple effect each year.

\subsubsection{Purification of Air Pollution $\left(\mathrm{NO}_{2}, \mathrm{SO}_{2}\right)$}

Related with the purification function of air pollution, the trading market of contaminants emission like $\mathrm{CO}_{2}$ exists in the

Table 5. Estimation Result of Carbon Reduction Effect

\section{$\mathrm{CO}_{2}$ Absorption}

Absorption amount of $\mathrm{CO}_{2}$ by trees in urban parks $\times \mathrm{CO}_{2}$ contaminant disposal cost (Carbon Emission) $\times$ Area of green land of Yongsan park $=1.54 \sim 24.6($ ton $/ \mathrm{ha} / \mathrm{yr}) \times 18,500 \sim 22,500($ won/ton $) \times 109.8 \sim 200.8(\mathrm{ha})$ $=3,128 \sim 111,143$ thousand won

\section{$\mathrm{CO}_{2}$ Stock}

Stock amount of $\mathrm{CO}_{2}$ by trees in urban parks $\times \mathrm{CO}_{2}$ contaminant disposal cost (Carbon Emission) $\times$ Area of green land of Yongsan park $=36.3 \sim 293.8($ ton/ha $) \times 18,500 \sim 22,500($ won/ton $) \times 109.8 \sim 200.8$ (ha) $=73,736 \sim 1,327,388$ thousand won country, but since it's the early stage of its execution, the indirect value was estimated by using the replacement cost method in this study. The purification amount of air pollutants by trees in Namsan and Jung-gu in Seoul and Yong-in in Gyeonggi province derived from the study of Joe, et al. $(2002,2003)$ was applied for the absorption amount of $\mathrm{NO}_{2}, \mathrm{SO}_{2}$ by trees in urban parks. For contaminants disposal cost, the imposing amount per $\mathrm{kg}$ of pollutants involved with the criteria of emission permission that is specified in 'The Special Law on Atmosphere Environment Improvement in Metropolitan Area' was established on the basis of replacement cost. The scale of market value of purification function of Yongsan park using replacement cost method is 3,343 thousand won to 25,564 thousand won every year in case of $\mathrm{NO}_{2}$, and 2,398 thousand won to 14,421 thousand won per year in case of $\mathrm{SO}_{2}$.

\subsubsection{Health Improvement by Improvement of Air Pollution} $\left(\mathrm{NO}_{2}, \mathrm{SO}_{2}\right)$

The data of health cost that was estimated by Joe, et al. (2004) was used to measure the cost of sanitation $\cdot$ health according to the improvement of air pollution. Accordingly, if the cost of health benefits by 1 ton reduction of air pollutants is applied, the indirect value of sanitation health according to the construction of Yongsan park is estimated to be 118 thousand won to 903 thousand won every year in case of $\mathrm{NO}_{2}$, and 108 thousand won to 647 thousand won per year in case of $\mathrm{SO}_{2}$.

Table 6. Estimation Result of Purification Effect of Air Pollution

\section{$\mathrm{NO}_{2}$ Purification}

$\mathrm{NO}_{2}$ removal amount of trees in urban parks $\times \mathrm{NO}_{2}$ contaminants disposal cost $\times$ Green land area of Yongsan park

$=10.5 \sim 43.9(\mathrm{~kg} / \mathrm{ha} / \mathrm{yr}) \times 2,900(\mathrm{won} / \mathrm{kg}) \times 109.8 \sim 200.8(\mathrm{ha})$

$=3,343 \sim 25,564$ thousand won $/ \mathrm{yr}$

\section{$\mathrm{SO}_{2}$ Purification}

$\mathrm{SO}_{2}$ removal amount of trees in urban parks $\times \mathrm{SO}_{2}$ contaminants disposal cost $\times$ Green land area of Yongsan park

$=5.2 \sim 17.1(\mathrm{~kg} / \mathrm{ha} / \mathrm{yr}) \times 4,200(\mathrm{won} / \mathrm{kg}) \times 109.8 \sim 200.8(\mathrm{ha})$

$=2,398 \sim 14,421$ thousand won/yr

Table 7. Estimation Result of Cost Reduction by Improvement of Air Pollution

\footnotetext{
$\mathrm{NO}_{2}$ Reduction

$\mathrm{NO}_{2}$ removal amount of trees in urban parks $\times$ Health improvement cost related with $\mathrm{NO}_{2} \times$ Green land area of Yongsan park

$=10.5 \sim 43.9(\mathrm{~kg} / \mathrm{ha} / \mathrm{yr}) \times 102.4$ (thousand won/ton) $\times 109.8 \sim 200.8(\mathrm{ha})$

$=118 \sim 903$ thousand won/yr
}

\section{$\mathrm{SO}_{2}$ Reduction}

$\mathrm{SO}_{2}$ removal amount of trees in urban parks $\times \mathrm{SO}_{2}$ contaminants disposal cost $\times$ Green land area of Yongsan park

$=5.2 \sim 17.1(\mathrm{~kg} / \mathrm{ha} / \mathrm{yr}) \times 188.4$ (thousand won/ton) $\times 109.8 \sim 200.8(\mathrm{ha})$

$=108 \sim 647$ thousand won $/ \mathrm{yr}$ 


\subsubsection{Urban Heat Island Mitigation}

The urban green land comprised of trees, herbs and soil has the effect of lowering air temperature through the role of evaporatio $\mathrm{n} \cdot$ diffusion and additionally through the function of blocking or absorbing solar radiation that reaches artificial structures or through the function of absorption (Joe, Hyun Gil, etc. 1999). The direct and indirect energy-saving effect by trees with application of the research result ( 10 to $35 \$$ per $100 \mathrm{~m}^{2}$ ) of Teha et al. (1996) was estimated in this study. As a result, if the decline function of urban heat island is evaluated with indirect value according to the construction of Yongsan park, it is estimated to be 129,547 thousand won to 827,408 thousand won per year.

\subsection{Estimation of Non-Using Value ${ }^{4)}$}

After establishing a simulated circumstance for visitors as a subject who will visit the park since Yongsan park is constructed in the future, non-using value can be estimated through preference for this. Currently, since Yongsan park is at the stage of

Table 8. Estimation Result of Urban Heat Island Mitigation Effect

\section{Value of Urban Heat Island Mitigation}

Energy-saving cost by urban trees $\times$ Area of green land in Yongsan park

$=118 \sim 412\left(\mathrm{won} / \mathrm{m}^{2} / \mathrm{yr}\right) \times 109.8 \sim 200.8(\mathrm{ha})$

$=129,547 \sim 827,408$ thousand won $/ \mathrm{yr}$ establishing a plan, there is a limit that facilities to represent the status of the park and various functions that visitors of the park expect can be expressed. Therefore, for the reasonable method to estimate non-using value of the park, it is more important to establish a simulated circumstance for Yongsan park and to estimate willingness-to-pay that visitors are willing to pay for each circumstance than any other thing. Considering these conditions, this study suggested many simulated optional alternatives for the construction of Yongsan park to potential visitors through Conjoint Analysis, and estimated its value through expressions of themselves.

The attributes of Yongsan park were established as the status of inside and outside the park, sports facility to make better use of a urban park, cultural facilities, extension of diversity of living things as an environmental and ecological park, and willingnessto-pay for the construction of Yongsan park, and the level of each attribute is shown as in Table 4 . The preliminary analysis was carried out by establishing it as 10 thousand won, 20 thousand won, and 40 thousand won in the pre-survey that was conducted to derive price attribute variable.

As a result, there were many opinions that there is no willingness to pay for visiting Yongsan park, and since a result that was overestimated was derived, 0 won, 2 thousand won, 4 thousand won and 6 thousand won that had no willingness-to-pay through the amount range of open questions when conducting pre-survey were established as a scope.

Table 9. Level and Scope of Attributes for Conjoint Analysis

\begin{tabular}{|c|c|c|}
\hline \multicolumn{2}{|c|}{ Attributes of Yongsan Park } & Level and Scope \\
\hline Status of Park & $\begin{array}{l}\text { Ethnicity } \cdot \text { Historicity } \\
\text { Centrism·Representativeness } \\
\text { (National Symbolic Park) }\end{array}$ & $\begin{array}{l}\text { Level 1. Current Status } \\
\text { Level 2. Urban Parks (Seoul Forest, Namsan Park) } \\
\text { Level 3. National Symbolic Park (Olympic Park) }\end{array}$ \\
\hline Sports Facilities & $\begin{array}{c}\text { Health·Sports Activities } \\
\text { Relaxation·Leisure Experience } \\
\text { Emotional and Psychological Stability }\end{array}$ & $\begin{array}{l}\text { Level 1. Current Status } \\
\text { Level 2. Basic Sports Facilities } \\
\text { Level 3. Basic Sports Facilities, Swimming Pool, Gym }\end{array}$ \\
\hline Cultural Facilities & Culture-Arts Experience & $\begin{array}{l}\text { Level 1. Current Status } \\
\text { Level 2. Exhibition Hall, Outdoor Sculpture Park } \\
\text { Level 3. Exhibition Hall, Outdoor Sculpture Park, Art Gallery, Museum, } \\
\text { Many kinds of Facilities for Performance }\end{array}$ \\
\hline Environment·Ecology Park & $\begin{array}{l}\text { Diversity of Creatures } \\
\text { Ecological Network }\end{array}$ & $\begin{array}{l}\text { Level 1. Tree } 70 \text { species, Animal } 5 \text { species } \\
\text { Level 2. Tree } 85 \text { species, Animal } 10 \text { species } \\
\text { Level 3. Tree } 100 \text { species, Animal } 20 \text { sepcies }\end{array}$ \\
\hline (Monthly & $\begin{array}{l}\text { Payment } \\
\text { yment per Household) }\end{array}$ & $\begin{array}{l}\text { Level 1. } 0 \text { won } / \mathrm{month} \\
\text { Level 2. } 2,000 \text { won } / \text { month } \\
\text { Level 3. } 4,000 \text { won } / \text { month } \\
\text { Level 4. } 6,000 \text { won } / \text { month }\end{array}$ \\
\hline
\end{tabular}

4) In general, non-use value, select the value, surrogate value, bequest value is divided into more explanation on this please refer to Joe, Yong Seong, Yang Hun Son(2004), "Estimation of Social Benefits by Atmosphere Pollution Improvement that Affects Health", Korean Association of Applied Economics, 23(1): 101-111. 
Table 10. Configuring the Sample Region and Age Group

\begin{tabular}{|c|c|c|c|c|c|}
\hline \multirow[t]{2}{*}{ Region } & Yongsan & Seoul* & $\begin{array}{l}\text { Incheon/ } \\
\text { Gyeonggi }\end{array}$ & Daejeon & Busan \\
\hline & 200 & 200 & 200 & 200 & 200 \\
\hline \multirow{2}{*}{ Ages } & $20^{\prime}$ & \multicolumn{2}{|c|}{$30^{\prime}$} & $40^{\prime}$ & over $50^{\prime}$ \\
\hline & 156 & \multicolumn{2}{|c|}{232} & & 335 \\
\hline
\end{tabular}

Note: * Seoul area except for Yongsan-gu

Table 11. Result of Conjoint Analysis for Value Estimation of Yongsan Park

\begin{tabular}{c|c|c|c|c|r|r}
\hline Park Attributes & Coef. & $\begin{array}{c}\text { MWTP } \\
\text { (Kor currency) }\end{array}$ & $\mathrm{z}$ & $\mathrm{P}>\mathrm{z} \mid$ & \multicolumn{2}{c}{$[95 \%$ Conf. Interval] } \\
\hline Status of Park & .529 & 686.34 & 8.55 & 0.000 & .650 \\
\hline Health/Sports Facilities & .499 & 647.54 & 7.95 & 0.000 & .41 & .38 \\
\hline Cultural Facilities & .487 & 631.92 & 7.71 & 0.000 & .36 & .611 \\
\hline Diversity of Creature & .139 & 181.05 & 2.25 & 0.024 & .018 & -.0008 \\
\hline Willingness to Pay & -.0008 & - & -37.43 & 0.000 & -.0007 \\
\hline Constant & -.740 & - & -22.39 & 0.000 & -.805 & -.675 \\
\hline Total Willingness to Pay & - & 2146.85 & - & - & - \\
\hline
\end{tabular}

\subsubsection{Configuring the Sample Region and Age Group}

The following form of indirect utility function $\left(V_{i j}\right)$ was made up to estimate the economic value of Yongsan park in The survey for acquiring data was conducted from Aug. 1st to Aug. 16th, 2010, and the subject of the survey was 1,000 men and women aged between 20 to 70 who live in Seoul City, Incheon and Gyeonggi province, Daejeon and Busan except for Yongsan- gu.

Random assignment sampling was conducted by considering the surveyed region, ages, monthly income level per household, and individual interview survey was implemented by using the structured questionnaire.

Especially, since statistical meaningfulness of willingness -topay is high, the willingness-to-pay for the value of Yongsan park could be trusted5). Looking through the willingness-to-pay, the value for 'Status of Park', 'Health·Sports Facilities', and 'Cultural Facilities' was highly evaluated, and it was found out that they didn't place a great value on the diversity of creature ${ }^{6}$ ).

5) Since the $z$ value of a park attribute exceeded 2, the statistical meaningfulness was secured.

6) Health-Aesthetic Stability, Relaxation-Amusement, Cultural Arts Experience Yongsan park's non-use value of properties, including properties of the region were defined as regions rather than using the same property values as properties of the region close to the pandandoem. However, the current composition of Yongsan park for any sports facilities or cultural facilities will be provided for specific situations because there is no master plan, sports facilities and cultural facilities, is too abstract for the property level, there are limitations.

\subsubsection{Design of Estimation Model for Non-Using Value}

The following form of indirect utility function $\left(V_{i j}\right)$ was made up to estimate the economic value of Yongsan park in this study.

$$
V_{i j}=\beta_{1} Z_{1, i j}+\beta_{2} Z_{2, i j}+\beta_{3} Z_{3, i j}+\beta_{4} Z_{4, i j}+\beta_{5} Z_{5, i j}
$$

The indirect utility function above is comprised of the status of a park $\left(\beta_{1} Z_{1, i j}\right)$, sports facilities $\left(\beta_{2} Z_{2, i j}\right)$, cultural facilities $\left(\beta_{3} Z_{3, i j}\right)$, diversity of creature $\beta_{4} Z_{4, i j}$, and linear function of willingness to pay $\left(\beta_{5} Z_{5, i j}\right) . \beta_{1} \sim \beta_{5}$ is estimation coefficient of individual attribute variables that affect the utility of respondents. At this time, MWTP (Marginal Willingness To Pay) that is for one unit increase from the current level of individual benefit attribute variables can be obtained by the total differential of the formula above.

\subsection{Estimation Result of Non-Using Value}

As a result of the analysis using multinomial logit model, it was analyzed that the average willingness to pay of respondents regarding Yongsan park was the level of 2,147won/month per household. If the result value is expanded to the total number of households in the country, the non-using value of Yongsan park is the level of 412 billion won every year7).

If the willingness to pay of a card that respondents selected by each region is compared, the difference in the value of Yongsan park can be found. As a result of Conjoint Analysis, the frequency

7) As the total number of households, 15,988,274 households were applied on the basis of total population and housing census by Statistics Korea in 2005. 
Table 12. Willingness To Pay for the Value of Yongsan Park by Regions (Korean Current)

\begin{tabular}{c|c|c|c|c|c}
\hline & Yongsan & Seoul* & Incheon/Gyeonggi & Daejeon & Busan \\
\hline Status of Park & 821.20 & 932.34 & 318.91 & 1181.79 & 868.92 \\
\hline Health/Sports Facilities & 131.80 & 724.35 & 167.84 & 1677.50 & 570.95 \\
\hline Cultural Facilities & 275.03 & 1053.08 & 92.92 & 851.65 & 845.97 \\
\hline Diversity of Creature & 491.73 & 400.35 & 58.15 & 483.79 & 285.73 \\
\hline Total Willingness to Pay & 1228.03 & 2709.77 & 579.67 & 3710.94 & 2285.86 \\
\hline
\end{tabular}

Note: * Seoul area except for Yongsan-gu

to select 'Current State (0won)' was dominantly high (69.38) only in Incheon-Gyeonggi Province, and mostly 'Level 2 (2,000won)' was chosen in other regions. In Yongsan-gu that is expected to get the largest benefit from the construction of the park as well, it was found that the ratio of selecting ' 0 won' for willingness to pay was relatively high.

\section{Ripple Effect of Construction Project of Yongsan Park}

\subsection{Analysis Method}

The project progressed by the financial investment of the government like Yongsan park creates various tangible, intangible effects through many paths from the start of a project that financial investment is made to the stage that the final object can be used, and these effects are called as ripple effects. The type of ripple effects becomes to appear with income within a region that arises from the investment of project cost, causing production of industries and job creation etc. and there is a feature that the size of each index is not involved with cost generation. The ripple effect means indirect and inductive effect, in other words, multiplier according to the progress of policy projects of the government at the dimension of regional economy, and the analysis of regional ripple effect is used for the same meaning as the analysis of multiplier effect.

The type of ripple effects by the progress of the construction project of Yongsan park was classified into primary direct effect and secondary, tertiary indirect effect. The primary direct effect is economic effect and includes production inductive effect focusing on industries according to the progress of a park construction project, value added creation effect by causing production and new job creation effect etc. The secondary, tertiary indirect effect is halo effect that appears with the background of Yongsan park after the construction of the park and can be classified into the increase of local taxes revenue and creation effect of tourism earnings and expenses.

\subsection{Direct Economic Ripple Effect}

When the construction of Yongsan park is set up as the project of construction sector, inter-industry analysis can be said to be a useful analysis technique in understanding national economic

\begin{tabular}{|c|c|}
\hline \multicolumn{2}{|c|}{ Prototypes of Construction Project Effect of Yongsan Park } \\
\hline 1st (Construction Process) & 2nd (After Construction) \\
\hline Direct Effect & Indirect Effect \\
\hline Causing Production Effect & $\begin{array}{c}\text { Increase of Local Taxes } \\
\text { Revenue } \\
\text { Creation Effect of Added Value } \\
\text { Job Creation Effect }\end{array}$ \\
$\begin{array}{c}\text { Increase of Tourists Inflow } \\
\text { Improvement of Tourism } \\
\text { Earnings and Expenses }\end{array}$ \\
\hline
\end{tabular}

Fig. 2. Prototypes of Ripple Effects According to Progress of Construction Project of Yongsan Park

ripple effects of Yongsan park construction. In this study, economic ripple effects were analyzed by using 'Regional Input-Output Table in 2005' that was announced by Bank of Korea in Nov. 2009. The whole country was divided into 5 metropolitan area for convenience of analysis, and the regional industries in regional input-output table were comprised of total 28 sectors including agricultural food and sea food, industrial products.

The final demand that is an exogenous variable must be understood to apply Input-Output model, and the project cost for the construction of Yongsan park corresponds to this. Since the concrete general basic plan is established, it is actually in the state that is impossible to estimate the exact cost at the point of analysis. Therefore, when referring to the construction cost of domestic and foreign parks and considering landscape construction for ecological restoration, the construction of connecting passageways, the construction of waterfront, the installation of cultural amenities etc. in Yongsan park, the total construction cost can be estimated to be the scale of $1,024.8$ billion won.

In the case that 1,024.8 billion won of the government finance is invested as the construction cost of Yongsan park, it is estimated to be the level that the amount of inducing production will be 2.6 trillion won, the amount of creating added value will be 809.6 billion won, and the employed personnel that are newly created will be 25,620 persons. The weight of metropolitan area in the nationwide economic ripple effects is the level of $65 \sim 78 \%$.

\subsection{Fluctuation of Local Taxes Revenue}

To analyze the influence of local taxes revenue according to the fluctuation of real estate price of surrounding area of Yongsan 
Table 13. Economic Ripple Effect

\begin{tabular}{c|c|c}
\hline Classification & Whole Country & $\begin{array}{c}\text { Metropolitan Area } \\
(\text { Ratio*) }\end{array}$ \\
\hline Production Induction & 2.6 trillion won & $\begin{array}{c}1.7 \text { trillion won } \\
(64.9 \%)\end{array}$ \\
\hline $\begin{array}{c}\text { Creation of Added } \\
\text { Value }\end{array}$ & 809.6 billion won & $\begin{array}{c}635.5 \text { billion won } \\
(78.5 \%)\end{array}$ \\
\hline $\begin{array}{c}\text { Creation of } \\
\text { Employment }\end{array}$ & 25,620 persons & $\begin{array}{c}17,549 \text { persons } \\
(68.5 \%)\end{array}$ \\
\hline
\end{tabular}

Note: * Metropolitan area ratio compared to the whole country

park, the influence of real estate price of Yongsan park needs to be estimated through proper analysis technique (Hedonic function etc.) with the fluctuation before the announcement of the park construction project, and after the announcement, and the fluctuation data of the real trading price after the construction. However, since the big time difference occurs until the year of 2017 which will be the 1st opening after the enactment of 'The Special Law on Yongsan Project Construction', there is a limit to apprehend the net effect of Yongsan park construction. To overcome this limit, it is intended to estimate indirectly the price fluctuation of real estate by utilizing the results of the preceding studies and based on that, to analyze a standard of assessment of the increase of local taxes revenue.

The majority of preceding studies that analyzed the effect of price fluctuation of apartments around a park green land show the result that the distance between the park green land and those apartments is in inverse proportion each other. There are 83 apartment complexes in 15 administrative district of Yongsan$\mathrm{gu}$, the average distance from Yongsan park is $719 \mathrm{~m}$. In this study, it was assumed that the effect of price increase of apartments that are separated more than average distance from Yongsan park would be insufficient. The price elasticity applied in this study referred to the cases of Seoul Forest (assumption 1) and Ttuksum park (assumption 2) ${ }^{8}$ ). As a result of analysis, in the case that assumption 1 is applied, the price of apartments in Yongsan-gu is expected to increase from minimum 270 thousand won to maximum 1.9 million won per $3.3 \mathrm{~m}^{2}$, and in the case that assumption 2 is applied, the price is expected to increase from minimum 180 thousand won to maximum 1 million won. This price increase of apartments can be lead to the increase of local taxes revenue of Yongsan-gu. In the case that it is assumed that the effect of Yongsan park construction lasts for around 30 years on the increase rate of the assessed value of apartment property tax according to the construction of Yongsan park, it is estimated that $15.6 \% \sim 29.7 \%$ of property tax revenue will be increased.

8) $\lambda_{1}$ is the assumption that 269 thousand won increases as it is getting $100 \mathrm{~m}$ closer on the basis of standard deviation $719 \mathrm{~m}$ (applied to Seoul Forest), $\lambda_{2}$ is one that 148 thousand increases as it is getting $100 \mathrm{~m}$ closer with $719 \mathrm{~m}$ as the center (applied to Ttuksum Park).
In the same way that the price increase of apartments of surround area according to the construction of Yongsan park is expected, the increase of land price will be continued. As a result of investigation of the declared value of lands around Seoul Forest, it was found that it increased by $50.57 \%$ at the end of 2006 which was one year passed since the opening of the park compared to the year of 2003 which was the point of the park construction. If this result is applied to Yongsan park, it can be assumed that the increase of land price would be at the level of $50 \%$ an it can be expected that a standard of assessment will be increased by approximately 1.5 times.

\subsection{Prediction of Demand of Tourism and Tourism Consumption Expenditure}

In the case that Yongsan park acts as new power of inflow for urban tourism in the country from a closed image that it has been used for army bases for 60 years or so in the past, it can be expected to create domestic and foreign tourism earnings and expenditure. In the survey of intention to visit Yongsan park, $78.6 \%$ of total 1,000 respondents said they would visit, and they responded they would visit average 4.1 times per year ${ }^{9)}$. The rate of willingness to visit (78.6\%) is applied on the basis of estimated future population in the country, and it is estimated that annual average 361 million persons would visit from 2017 to 2030. If this is viewed on the basis of average cost 12,416 won per capita that is spent when visiting Yongsan family park, the scale of tourism consumption with the level of minimum 448.2 billion won can be expected every year.

In the case that the visiting consumption of Yongsan park is estimated by using the rate of foreign tourists visiting the surrounding area of Yongsan park such as Yitaewon, Namsan etc, it is expected that around 1.2 million persons to 2.52 million persons would visit Yongsan park per year ${ }^{13)} 10$ ). In the case that the spending amount on the surrounding area of Yongsan park is assumed to be the level of $20 \%$ among 1,224 dollars that is the average expenditure per capita of foreign tourists, the scale of consumption expenditure according to foreign tourists reaches from minimum 352.3 billion won to maximum 740.9 billion won per year.

\section{Conclusion and Suggestion of Policy}

\subsection{Conclusion Remarkable}

Considering that Yongsan park is an urban park that the

9) This survey was conducted with the survey on the previously mentioned value of Yong-San park. (1,000 persons in 5 regions including Incheon, Seoul City etc. from Aug. 1st to Aug. 16th, 2010).

10) It is assumed that $77.4 \%$ of $7,815,553$ foreign tourists who visited Korea visit Seoul, and it is the result by multiplying $19.7 \%$ that is visiting the surrounding area of Yongsan park such as Yitaewon etc. by $32.2 \%$ that is visiting Namsan among them. 
government finance is invested for the first time in the country, this study was intended to calculate values that national intention was reflected and to derive political implications that could increase using value of the park in the future by estimating economic effect of the project implementation.

In this study, the value of Yongsan park was divided into using value and non-using value. The using value is environmental material and the value of Yongsan park was estimated, and the non-using value was estimated on the basis of people's willingness to pay for various attributes and functions of Yongsan park. First, it is expected that since Yongsan park is able to provide largescaled green land and open space within the center of the city, it will be environmental material having the value from 200 million won to maximum 2.3 billion won per year such as carbon reduction effect, urban heat island mitigation, purification of air pollution, and health improvement effect etc. Other than this using value, as a result of estimating non-using value on the basis of people's willingness to pay for functions and attributes of Yongsan park, it is acknowledged to have the value with the level of 454.4 billion won every year.

1 trillion and 24.8 billion won or so is required for the construction of Yongsan park, and it is expected to have ripple effects such as 2.6 trillion won for production induction effect, 809.6 billion won for induction of added value and new job creation for 25,620 persons.

It is analyzed that since the construction of Yongsan park has a meaningful influence on the price increase of real estate of the surrounding area by the provision of large-scaled green land space, the positive external effect will be generated. Especially, in case of apartments, it is expected that a standard of assessment will increase by around $3.1 \% \sim 5.7 \%$, and the land of the surrounding area will increase by around $150 \%$, and ultimately the local taxes revenue (property tax) of Yongsan-gu will increase.

Also, as a result of predicting the visiting demand of Yongsan park, it is estimated that annual average 30 million or so persons will visit including foreign tourists from 2017 to 2030. Based on this tourism demand, it is estimated that the creation of tourism income by local people will be from 368.8 billion won to maximum 471.8 billion won per year, and by foreigners will exceed 352.8 billion won.

\subsection{Suggestion of Policy}

This study is one reflecting national intention for economic values and benefits of Yongsan park, and the real value from the view of uses was objectively estimated. The result of this study provides quantitative information for the value of public interest by functions of Yongsan park and can be utilized as basic data when establishing the park plan and an operation plan. Looking through the value of Yongsan park and the effect of the project implementation, it has sufficient feasibility for the investment of the government finance, and the following political alternatives can be suggested.
First, the strategy to spread wide understanding for the appropriateness of the park construction is necessary to raise successful using value of Yongsan park. As a result of this study, it was found that since the recognition on the necessity of the park construction and intention to use the park in the future and value is low especially in the metropolitan area (Gyeonggi, Incheon) except for Seoul, promotional strategies for them would $b$ necessary.

Second, despite the investment of the central government finance, since the benefits from Yongsan park are expected to be concentrated on nearby areas of Seoul, the efficiency of the financial investment must be prepared. In other word, it's because while local taxes revenue of Seoul City and Yongsan-gu increases and financial benefits are converged, the burden of financial investment is given to the whole nation. Therefore, it is necessary for the central government to make an effort to internalize benefits. When required, a sophisticated model for the distribution of benefits between the central government and local autonomous entities must be developed regarding burden sharing and redemption of benefits for the construction of Yongsan park.

\subsection{Limitations and Future Direction of Complementary}

This study aims to estimate the value of Yongsan Park and estimate the economic effect of the park construction project itself. For the first part, we divide the values into using and non-using values and evaluate them by estimating the effect of pollution mitigation and using conjoint analysis of park attributes. For the second part, the regional I-O analysis is used to estimate the ripple effect of the project.

However, in this study, following the analytical method has two limitations. First, the calculation method for conjoint for the MWTP in the process, second, air purification is the double counting, partially.

A unit of the property by improving the level MWTP were assumed the same qualitative properties as in the present study, assuming the level of the first improvements in the properties for the second property MWTP and second, the third property, improve property MWTP can not be the same for the level of each attribute by separating the individual level should be estimated MWTP.

In this study, however, an indirect utility function coefficients of the size of the American MWTP equally by minute by calculating the size of the property improvements has limitations could not be differentiated. However, conjoint analysis, which is recognized as the maximum threshold, so the next complementary studies are deemed necessary.

In addition, air purification is partially double counting, but we do not resolve the problem. In other words, since the value of purification of air pollution $\left(\mathrm{NO}_{2}\right.$ and $\left.\mathrm{SO}_{2}\right)$ was already counted in, its effect of health improvement due to the purification should not be counted again. For improving health in this study the effect of pollutants according to purify the cost of health improvement 
is calculated separately based on the composition. So, Yongsasn Park improve the environment can be utilized to estimate the effect.

\section{References}

1. Planning Group for Progress of Yongsan Park Construction (2009), The Study by Functions of Yongsan Park for Constructing BrandName Park, Ministry of Land, Transport and Maritime Affairs.

2. Kim, J. H. (2006), Economic Value of Environmental Material and Social Cost of Environmental Pollution : Jipmundang, Seoul.

3. Gwak, S. J., S. H. Yu, and J. I. Jang (2006), "Value Estimation of the Mouth of Han River Using Conjoint Analysis", Study of Economics, 23(2): $95 \sim 101$.

4. Son, S. R. and B. G. Yun (2002), "The Study on Values of Park Green Land of People in a City", Land Study, Korea Research Institute For Human Settlements, 45(3): 85 92

5. Im, H. J., S. H. Yu, and S. J. Gwak (2006), "Estimation of Economic Benefits of Seoul Forest Construction in Seoul", Regional Study, 39(4): $72 \sim 88$.

6. Akbari, H. (2002), "Shade trees reduce building energy use and $\mathrm{CO}_{2}$ emissions from power plants" Environmental pollution, 116: 852 867.

7. Joe, H. G. (2001), “A Study of Economic Value of Urban Park After Changes of Environments", Seoul National Unversity MA degree paper, Seoul.

8. Joe, Y. S. and Y. H. Son (2004), "Estimation of Social Benefits by Atmosphere Pollution Improvement that Affects Health", Korean Association of Applied Economics, 23(1): $101 \sim 111$.

9. Joe, Y. H. and H. G. Joe (2002), "Effect of Air Purification of Urban
Green Land in Seoul", Journal of The Korea Society of Environmental Restoration Technology, 24(6): 152 161.

10. Joe, H. G. and T. W. Ahn (1999), "Function of Microclimate Improvement by Urban Green Land", Journal of The Korean Institute of Landscape Architecture, 32(2): 62 87 .

11. Joe, H. G., Y. H. Joe and T. W. Ahn (2002), "Function and Value of Air Purification of Urban Natural Park in Namsan, Seoul”, Journal of The Korean Society of Environment \& Ecology, 47(3): 99 107.

12. Joe, H. G., Y. H. Joe and T. W. Ahn (2003), "Effect of Atmospheric Environment Improvement of Urban Green Land : Focusing on Jung-gu in Seoul City", Journal of The Korean Institute of Landscape Architecture, 22(4): $81 \sim 96$.

13. Joe, H. G. and T. W. Ahn (2003), "The Role of Air Purification of Trees in Urban Ecosystem", Journal of The Korean Institute of Landscape Architecture, 21(3): $43 \sim 49$.

14. On NuRi (2008), Estimation of Environmental Benefits of Yongsan Park By Contingent Valuation Method, Yonsei university MA degree paper.

15. Peter H. (2007), The Excellent Urban Park System And How Much Value it Brings to a City: McHill, NewYork.

16. R. Schmidt (2007), Parks and Open Space; Duties and Responsibilities in Contemporary Landscape Architecture: Oxford, London.

17. Son, S. R., and S. J. Kwon (2001), "The Study on Development and Preservation of Green Space", Land Research, 54(2): 112 119.

18. GHG Certification Office, Korea Energy Management Corporation (http://www.kemcocdm.or.kr/).

19. Europe Climate Change Exchange (http://www.ecx.eu/).

20. Earth Charter Campaign (http://www.z9.or.kr).

21. Air Pollutants Emission Electronic Trading System (http://www.emissiontrade.go.kr). 